\title{
A 68 Year-old Woman With Leukemia Under Her Skin
}

\author{
Ben Creelan, MD, Hari Nair, MSIII, and Joanne Filicko-O'Hara, MD
}

\section{Introduction}

A wide spectrum of skin manifestations occurs in leukemia. Skin lesions are often due to infection, drug reaction, or inflammation. ${ }^{1}$ Rarely, extramedullary leukemia can invade the skin and is called leukemia cutis. ${ }^{2}$ Leukemia cutis is the infiltration of neoplastic leukocytes into the dermis or subcutaneous tissue, resulting in an identifiable skin lesion. These lesions show a varied morphology, and confirmatory immunohistochemical stains are needed for the diagnosis. Leukemia cutis may occur before, after, or concomitantly with the onset of systemic leukemia. ${ }^{3}$ Here we report a case of leukemia cutis occurring simultaneously with newly diagnosed acute myelogenous leukemia.

\section{Case Report}

A 68 year-old Caucasian female presented with a dry cough and malaise for two weeks. She noted fever as high as $101^{\circ} \mathrm{F}$ for the past two days. The patient reported visiting her primary care physician the previous week for routine lab work. She was contacted by her primary doctor and told to go to the ER because of decreased platelets and increased white blood cells. The patient did not take any medications. Past medical history was significant for spinal surgery in 1996 and 2001, which was complicated by superficial bacterial infection. She had never smoked, used alcohol or illicit substances. Allergy and family history was noncontributory.

Figure 2. Dermal biopsy of the skin lesion demonstrates infiltrating atypical cells (image A) expressing myeloperoxidase and focally CD38 (image B).

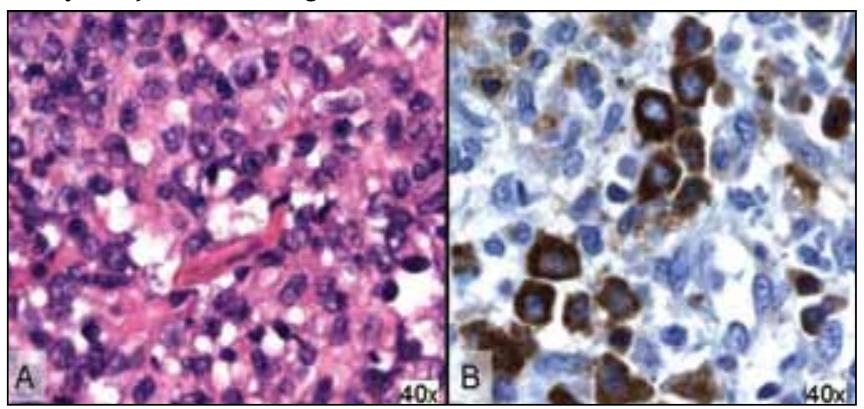

Physical exam was significant for a papule on the right cheek. This erythematous, firm papule had well-defined borders measuring approximately $3 \times 2 \mathrm{~cm}$ above the nasolabial fold on the right cheek (Figure 1). The patient attributed this to mosquito bites during a recent weekend camping trip. Laboratory testing revealed leukocytosis $(30 \times 109 / 1)$, anemia $(7.3 \mathrm{~g} / \mathrm{dL})$ and

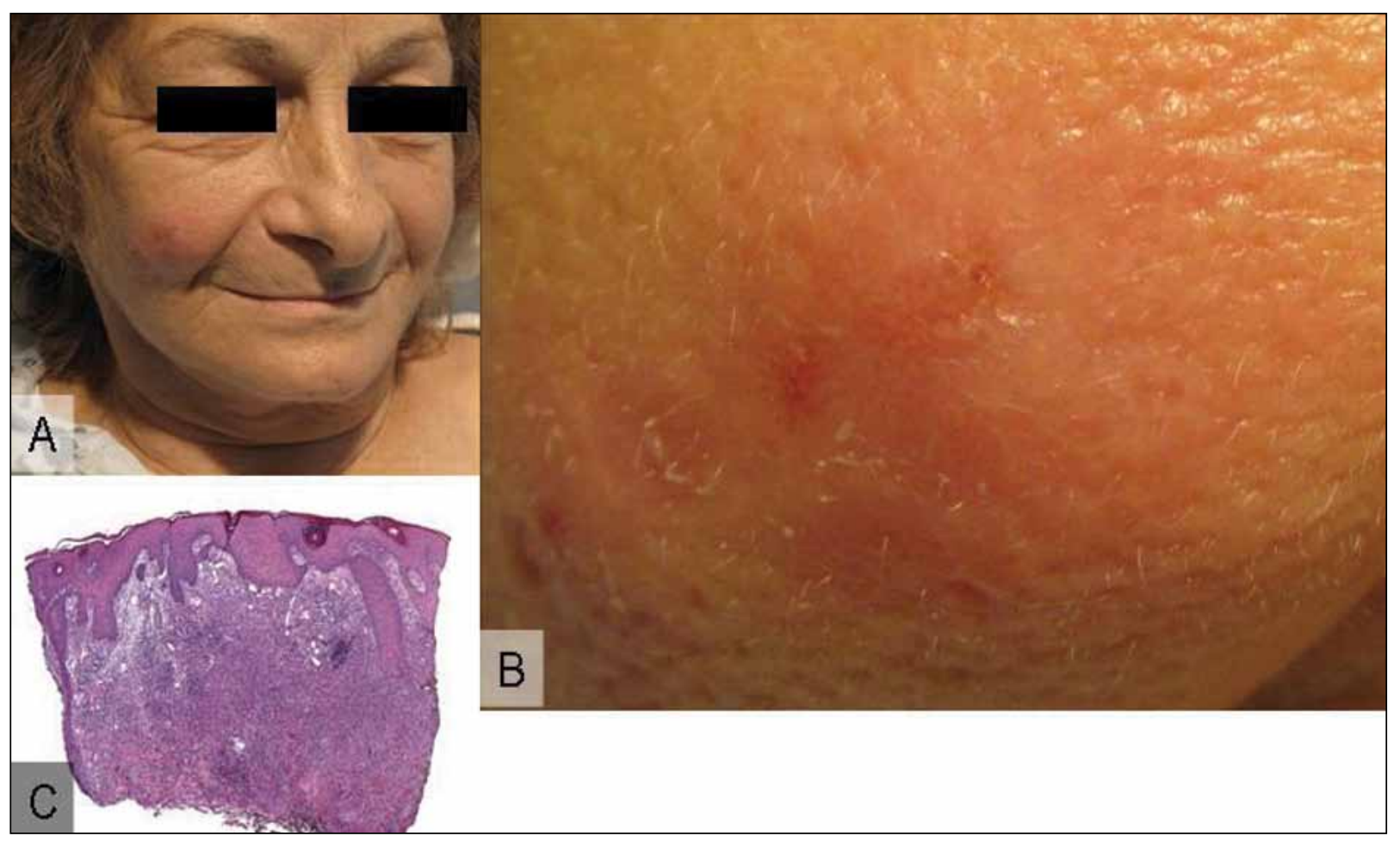

Figure 1. An erythematous firm papule is located on right facial cheek of the patient. 
thrombocytopenia (50 x 109/l). Manual differentiation revealed $31 \%$ blast cells. Bone marrow biopsy revealed acute myelogenous leukemia with multilineage dysplasia (AML, FAB M4). A single punch skin biopsy to a depth of 40 millimeters was performed. The biopsy showed dermal infiltrates of atypical cells expressing myeloperoxidase and focally CD38 (Figure 2). A c-kit stain revealed infiltration of mast cells consistent with leukemia cutis. The patient was treated with induction cytarabine and idarubicin, and her leukemia cutis lesion resolved within one week of initiation of chemotherapy. Her day \#14 and day \#30 bone marrow biopsies revealed no residual neoplastic disease.

\section{Discussion}

Patients with AML generally present with vague complaints related to complications of pancytopenia including weakness and easy fatigue. ${ }^{4}$ Skin findings in AML commonly include pallor, petechiae, or ecchymoses. Leukemic involvement of the skin is uncommon. When present, it is most often found in patients with monocytic or myelomonocytic AML variants. ${ }^{5}$ The overall incidence of leukemia cutis in AML is unclear but varies from 3\% to $13 \%$ in separate case series. ${ }^{6}$ About $23 \%$ to $44 \%$ of leukemia cutis is diagnosed at the same time as the systemic malignancy, as in our case. Less than $10 \%$ are discovered before systemic disease can be identified, and the remainder of cases appears afterwards. ${ }^{7}$ The frequency of leukemia cutis is much higher in children with congenital leukemia; in fact as many as $25 \%$ to $30 \%$ of infants develop cutaneous involvement. In contrast to adult disease, this does not confer a worse prognosis. ${ }^{8}$

Leukemia cutis is due to the local proliferation of leukemic cells into the dermis, epidermis, and subcutaneous tissue. The underlying molecular basis for the migration of leukemic cells to the skin is still unclear. It is hypothesized that the two ligands, Thymus Activation-Regulated Chemokine (TARC/CCL17) and Macrophage-Derived Chemokine (MDC/CCL22) are expressed on the skin, which attract adult T-cell leukemic cells to the skin. $\mathrm{T}$-cell related antigens are also present on the cell surface of leukemic cells in acute monocytic leukemia (AML-M5), which may promote selective tropism of these cells to the skin surface. ${ }^{9}$ Additional studies have shown Cutaneous Lymphocyteassociated Antigen (CLA) staining in $78 \%$ of patients with myelomonocytic leukemia cutis patients, suggesting that CLA may play a role in leukemic invasion of the skin. ${ }^{10}$

The classic lesions of leukemia cutis are red-brown to violaceousplum papules or plaques of varying sizes. ${ }^{11}$ The legs are involved most commonly, followed by arms, back, chest, scalp and face. Due to the varied clinical presentation, a biopsy of the lesion with immunohistochemical studies is often necessary. Histological findings of leukemia cutis typically show a diffuse infiltration of leukemic cells in the dermis and subcutaneous tissue, often squeezed between collagen bundles. Involvement of blood vessels and skin adnexa are seen in the granulocytic, monocytic and myelomonocytic variants of leukemia cutis. ${ }^{12}$

The development of leukemia cutis portends a poor prognosis in adults. More than $90 \%$ of these patients will have other sites of extramedullary involvement, and in $40 \%$ of these cases, the meninges will be involved. ${ }^{13,14}$ The disease course is usually aggressive, and length of survival is short. Studies have shown that the average survival time in AML patients with leukemia cutis is 7.5 months, and the overall survival rate is $6 \%$ at 2 years compared to $30 \%$ in AML patients without leukemia cutis ${ }^{15}$. Even with this poor prognosis, long-term disease-free survival is possible with curative therapy directed at the skin, bone marrow and other sites of extramedullary involvement. ${ }^{16}$

\section{References}

1. Desch JK. The spectrum of cutaneous disease in leukemias. J Cutan Pathol 1993; 20:407.

2. Agis $\mathrm{H}$, Weltermann A, Fonatsch $\mathrm{C}$, et al. A comparative study on demographic, hematological, and cytogenetic findings and prognosis in acute myeloid leukemia with and without leukemia cutis. Ann Hematol 2002; 81:90-5.

3. Cibull TL, Thomas AB, O’Malley DP . Myeloid leukemia cutis: a histologic and immunohistochemical review. J Cutan Path 2008; 35:180-5.

4. Meyers CA, Albitar, M, Estey, E. Cognitive impairment, fatigue, and cytokine levels in patients with acute myelogenous leukemia or myelodysplastic syndrome. Cancer 2005; 104:788.

5. Ratnam KV, Khor CJ, Su WP. Leukemia cutis. Derm Clin 1994; 12:419.

6. Baer MR, Barcos M, Farrell H, et al. Acute myelogenous leukemia with leukemia cutis. Eighteen cases seen between 1969 and 1986. Cancer 1989; 63:2192-200

7. Cho-Vega JH, Medeiros LJ, Prieto VG, et al. Leukemia cutis. Am J Clin Path 2008. 129:130-42

8. Fender AB, Gust A, Wang N, et al. Congenital leukemia cutis. Ped Derm 2008 25:34-7.

9. Yoshie O, Fujisawa R, Nakayama T, et al. Frequent expression of CCR4 in adult $\mathrm{T}$-cell leukemia and human T-cell leukemia virus type 1-transformed T cells. Blood 2002. 99:1505-11.

10. Petrella T, Meijer CJ, Dalac S, et al. TCL1 and CLA expression in agranular CD4/CD56 hematodermic neoplasms and leukemia cutis. Am J Clin Pathol 2004 122:307-13.

11. Su WP, Buechner SA, Chin-Yang L. Clinicopathologic correlations in leukemia cutis. J Am Acad Dermatol 1984; 11:121-8.

12. Buechner SA. Li CY. Su WP. Leukemia cutis: A histopathologic study of 42 cases. Am J Dermatopath 1985; 7:109-19.

13. Baer MR, Barcos M, Farrell H, et al. Acute myelogenous leukemia with leukemia cutis. Eighteen cases seen between 1969 and 1986. Cancer 1989; 63:2192-200.

14. Ratnam KV, Khor CJ, Su WP. Leukemia cutis. Derm Clin 1994; 12:419-31.

15. Kaddu S, Zenahlik P, Beham-Schmid C, et al. Specific cutaneous infiltrates in patients with myelogenous leukemia: a clinicopathologic study of 26 patients with assessment of diagnostic criteria. J Am Acad Dermatol 1999; 40:966-78.

16. Bohgaki T, Notoya A, Kondo M, et al. Leukemia cutis in an elderly patient treated with low dose cytosine arabinoside and etoposide. Leuk Lymphoma 2001; 40:433-6, 2001 